\title{
Brain-Computer Interfaces and Creative Expression: Interface Considerations for Rehabilitative and Therapeutic Interactions
}

\author{
Stephanie M. Scott* and Chris Raftery \\ Department of Journalism and Media Communications, Colorado State University, Fort Collins, CO, United States
}

By translating brain signals into new kinds of outputs, Brain-Computer Interface $(\mathrm{BCl})$ systems hold tremendous potential as both transformative rehabilitation and communication tools. BCls can be considered a unique technology, in that they are able to provide a direct link between the brain and the external environment. By affording users with opportunities for communication and self-expression, $\mathrm{BCl}$ systems serve as a bridge between abled-bodied and disabled users, in turn reducing existing barriers between these groups. This perspective piece explores the complex shifting relationship between neuroadaptive systems and humans by foregrounding personal

Edited by: Anton Nijholt, University of Twente, Netherlands

Reviewed by: Juliet L. King, George Washington University, United States

Melody Moore Jackson, Georgia Institute of Technology, United States

*Correspondence:

Stephanie M. Scott SMS.Scott@colostate.edu

Specialty section:

This article was submitted to Human-Media Interaction, a section of the journal Frontiers in Computer Science

Received: 01 June 2021 Accepted: 16 November 2021 Published: 09 December 2021

Citation: Scott SM and Raftery C (2021) BrainComputer Interfaces and Creative Expression: Interface Considerations for Rehabilitative and

Therapeutic Interactions. Front. Comput. Sci. 3:718605. doi: 10.3389/fcomp.2021.718605 experience and embodied interaction as concepts through which to evaluate digital environments cultivated through the design of $\mathrm{BCl}$ interfaces. To underscore the importance of fostering human-centered experiences through technologically mediated interactions, this work offers a conceptual framework through which the rehabilitative and therapeutic possibilities of $\mathrm{BCl}$ user-system engagement could be furthered. By inviting somatic analysis towards the design of $\mathrm{BCl}$ interfaces and incorporating tenets of creative arts therapies practices into hybrid navigation paradigms for self-expressive applications, this work highlights the need for examining individual technological interactions as sites with meaning-making potentiality, as well as those conceived through unique exchanges based on user-specific needs for communication. Designing $\mathrm{BCl}$ interfaces in ways that afford users with increased options for navigation, as well as with the ability to share subjective and collective experiences, helps to redefine existing boundaries of digital and physical user-system interactions and encourages the reimagining of these systems as novel digital health tools for recovery.

Keywords: brain-computer interface, multimodal communication, digital creative therapy, social technology, hybrid interfaces

\section{INTRODUCTION}

As the field of Brain-Computer Interface (BCI) technology continues to progress rapidly, it is anticipated to serve a vital role in future rehabilitation interventions for individuals experiencing neurological and/or movement disorders. Although there are various considerations for improving the accuracy and reliability of BCI systems, modern advancements within the field concern the potential of developing a system that allows immediate feedback for cognitive rehabilitation, as well 
as a suitable hybrid $\mathrm{BCI}$ for enabling creativity (Tan and Nijholt, 2010; Nishimura et al., 2010; Bamdad et al., 2015; Botrel et al., 2015; Kuibler and Botrel, 2019; Nijholt, 2019). Recent research suggests that hybrid BCIs may improve overall BCI performance through combing different features of brain signals, which can include the use of two BCI navigational paradigms (for example: SSVEP and imagined movement), or through integrating BCI and another system (for example, an eye-tracker) (Bamdad et al., 2015; Todd et al., 2012). Hybrid BCIs can either simultaneously process input or operate these systems sequentially and may offer an application that can improve overall performance and enhance user experience (Todd et al., 2012).

Despite the potential for BCI systems to serve as both rehabilitation and communication tools, art and creative expression are often overlooked in assistive technology (AT) development (Huggins et al., 2019). Exploring BCI and neurofeedback development through introspective approaches highlights how novel integrative applications may provide opportunities to improve well-being resources for less-explored populations of users and underscores the importance of the user (Rapoport et al., 2008; Zickler et al., 2013; Kubler et al., 2013; Kübler et al., 2015; Morone et al., 2015; Daly and Huggins, 2015). Adapting technologies to enable digital creativity by combining professional art and music therapy practices with technical components of a responsive closed biofeedback loop may contribute to meaningful and self-expressive processes. As such, it is important to consider how applying digital forms of creative participation in BCI-enabled spaces via the use of internal and external feedback (both visual and auditory) can shape meaning, enhance experience, and support wellbeing for users. Utilizing theoretical tenets of communication and creative arts therapies disciplines to help guide development of these systems as innovative digital health tools, we invite consideration of the communities of practice that envelop social and technological uses of these technologies. In applying hybrid forms of navigation to further increase successful user-system literacy rates as well as encourage neuroplasticity regeneration, this work suggests that integrating multifaceted design perspectives into the design of $\mathrm{BCI}$ interfaces will support opportunities for more inclusive and diverse interactions.

\section{TECHNOLOGICAL CONSIDERATIONS FOR HYBRID INTERFACES}

Advances in neuroadaptive technologies, specifically BCIs, have the potential to become a "major tool for people with disabilities to control locomotion and communicate with surrounding environment and, consequently, improve the quality of life for many affected persons" (Bamdad et al., 2015, p. 355). Electroencephalography, (i.e., electrical field recording at the scalp) has the most potential for clinical application, as it is relatively simple compared to other options, and is cost effective (Bamdad et al., 2015). However, several aspects of this technology will need improvements to assist efforts to uncover new patterns of brain activity underlying artistic creation. (Rapoport et al., 2008; Tan and Nijholt, 2010; Bamdad et al., 2015; Huggins et al., 2019). By affording users equal opportunities to engage in creative activities for expression, these systems can serve as a bridge between abled-bodied and disabled users and help to reduce existing barriers between these groups (Todd et al., 2012; Kübler and Botrel, 2019).

Orndorff-Plunkett et al. (2017) suggest that experimental exploration of neuronal activity can benefit social neuroscience, arguing that processes such as neuro- and biofeedback enable individuals to sense and interact with their own brain activity, from which causal conclusions in relation to individual behaviors, thoughts, perceptions, and experiences can be drawn (Orndorff-Plunkett et al., 2017). The notion of giving free and open choice of mental commands is notable since, on average, participants performed best with mental commands within a sensory modality they found more interesting and that corresponded to previous experience (Friedrich et al., 2012; Dhindsa et al., 2017a; Dhindsa et al., 2017b). More specifically, BCIs designed for artistic or creative applications, or BCIs that allow mental commands involving abstract visual or auditory imagery, may need to consider the artistic background of the user during training (Dhindsa et al., 2017b).

When incorporated into existing art-based BCI programs, designs focused on user-centered experience such as openended BCIs (Dhindsa et al., 2017a; Dhindsa et al., 2017b) and hybrid BCIs (Müller-Putz et al., 2015) have demonstrated the ability to uncover new patterns of brain activity underlying artistic creation and/or creative expression, further highlighting how applying insights from multiple disciplines can help identify gaps in interface design that reduce BCI usability (Kübler et al., 2013; Kübler et al., 2015; Müller-Putz et al., 2015; Cruz-Garza et al., 2019; Scott et al., 2019). Additionally, integrating neurofeedback applications within BCI offers clinical benefits to users through novel interventions grounded in psychological and neurosciences practices. The potential for BCI devices to facilitate general populations through neuro- and bio-feedback systems known as neurotherapeutic interventions "may give individuals a more active role in their own health care, utilize a holistic approach to body, mind, and spirit, are non-invasive, and elicit the body's own healing response" while also possessing the ability to inform social neuroscience and clinical communities" (King, 2016; Orndorff-Plunkett et al., 2017, p. 14; Scott and Gehrke, 2019; Scott et al., 2019).

\section{CREATIVE APPROACHES TO INTERFACE AFFORDANCES}

Acknowledging the reciprocal relationships between art, science and technology provides an opportunity to examine existing $\mathrm{BCI}$ interfaces from alternative perspectives, prompting additional research on how to improve, enhance, supplement, and allow $\mathrm{BCI}$ technologies to provide opportunities for creative expression and therapeutic care. (Wolpaw et al., 2002; Wolpaw and Wolpaw, 2012; Brunner et al., 2015). Expanding existing creative forms of expression for BCI systems in the form of digitally adapted creative arts therapies practices may provide different user groups the ability to communicate that which might otherwise go unexplored or un-interpreted, as it offers a medium for 
conveying subconscious emotions through new forms of selfexpression within a therapeutic relationship (Stewart, 2004; Angheluta and Lee, 2011; Ehresman, 2014; King, 2018).

Research has demonstrated that integrating artistic practices into rehabilitative treatments through which patients are able to create or co-create art themselves improves patient-physician communication, facilitates patient thinking, and improve clinical outcomes (Sonke, 2016). Additionally, creative arts therapies have been shown to positively impact various psychological and physiological outcomes through the interactive processes of action and experiential-based training (King and Pascuzzi, 2018; de Witte et al., 2021). Initial creative arts therapy practices have been redefined through various interdisciplinary and collaborative efforts to maintain a focus on enhancing and humanizing the healthcare environment (Sonke, 2016). More recently, research on clinical and evidence based creative expression in the form of creative arts therapies, which includes art and music therapies, has demonstrated the potential for better understanding of specific health conditions while offering a safe and cost-effective intervention as an adjunct to traditional medical management (King et al., 2019; Scott et al., 2019; de Witte et al., 2021; King and Parada, 2021).

Exploring the connection between the brain and expression through feedback loops that initiate interactive processes, whether generated through bio-signals using a BCI system or via creative processes, requires an individual to become aware of information and learn how to use it in ways that enable communication. Furthermore, co-integrating both types of feedback loops within technological system designed to serve a therapeutic purpose may reveal a third type of loop that assumes a top-down approach; one which affords individuals the ability to rehabilitate the brain through guided feedback by using artistic and musical therapy as expression planes. This has the potential to help those who struggle with traditional learning practices to better communicate their experiences and promote their own processes of healing and recovery (Kaimal, 2019; King and Kaimal, 2019).

\section{THEORETICAL PERSPECTIVES TOWARDS HUMAN-TECHNOLOGY RELATIONSHIPS}

Acknowledging the relationships and interactions that develop via system engagement as unique exchanges between the human and nonhuman components highlights how technological artefacts influence the processes and production of scientific practices and knowledge. The process of recognizing material, social, and natural things invite analytical strategies that can assume more collective and habitable spaces for construing knowledge, as scientific discovery is bound by the material objects and things that compromise the scientific processes of experimentation and observation (Latour, 2009). By engaging an empirically open ethnomethodology that dissolves the boundaries between things that are considered "social" from those that are deemed "natural," Latour (2009) suggests this process of relocation and re-embodiment of science through organized "networks of actants" and allows access towards conceptualizing how the environment is assembled. In-depth analyses of user-system interactions from these combined perspectives presents the added opportunity of engaging ethnographic methodologies, as well as interpretive and semiotic frameworks towards understanding user-system relationships as meaningful structures that are created and understood within cultural contexts (Geertz, 1973).

Engaging a postphenomenological approach towards articulating modes of knowledge as "embodied and situated" with mediated human-technological interactions enables analytical inquiry into the ways in which BCI engagement influences experience, shapes expression and impacts communication processes (Rosenberger and VerBeek, 2015, p. 1). Embodied relations through a mediated technology "simultaneously magnify or amplify and reduce or place aside what is experienced," shaping user perception and translation through "non-neutral" device characteristics (Idhe, 1990, p. 76; Rosenberger and VerBeek, 2015), implying that the ways in which knowledge and experience are construed through BCI usersystem engagement is of moral and ethical importance.

A deeper understanding of why this philosophical lens is important comes from recognizing how this perspective integrates tenets from two separate yet complementary paradigmatic frameworks-critical and constructivist (Rosenberger and VerBeek, 2015, p. 9). From a critical standpoint, it encourages dialogue between an investigator and subjects, and acknowledges findings as value-mediated while emphasizing that "researcher-researched relationships" should be built on mutual respect between equals. In this, BCI researchers, engineers, designers, etc., should not be objectively distanced from the users that are contributing to their research objectives, and BCIs should be developed in way that lends agency and equal voice to users. From a constructivist viewpoint, it recognizes that knowledge is built through user constructions and reconstructions, as well as through engagement and active participation to stimulate changes. This concept reinforces cooperation between a researcher and a user, weighing the power structure of what is possible through device affordances is of consequence (Lincoln and Guba, 1989; Guba and Lincoln, 1994, p. 230; Nisbet and Scheufele, 2009). As these paradigms maintain similar epistemological assumptions, this approach allows for both analytical critique and inquiry towards the multifaceted components of BCI systems, recognizing these devices as a composite product of technological affordances, mediated interactions with the technology, and the communication that occurs between the user and the system, as well as with researcher (Scott et al., 2019).

\section{EMBODIED DISCOURSE OF SOCIALLY INTERACTIVE SPACES}

Situating our conceptual sense of realities as grounded through metaphor and language illustrates the ways in which the design of BCI interfaces can guide new interpretations for user-system interactions (Lakoff and Johnson, 2003). By using the framework of distributed cognition as a lens through which to unite the concept of technologically-mediated social aspects of communication enabled by BCI systems with the broader mind-body processes, researchers can account for the ways in which understanding, knowledge, and perceptions are integrally situated within the articles, tools and people within our surrounding environments. 
Acknowledging BCI interactions as embodied symbolic spaces through which both internal and external representations work together to specify the distributed representational space offers insight towards how these processes negotiate intrinsic (user) and environmental (technology) structural affordances in order to share information and build knowledge. Interactions cultivated through system engagement allows relationships to form and offers sites of meaning that can co-create knowledge potentials between "an individual mind and an external artifact and between individual minds" (Zhang and Patel, 2006, p. 333). This view invites further inclusive and perceptual consideration by offering a perspective that extends essentialist and normative assumptions towards use and development of these systems (Zhang and Norman 1994; Salomon, 1997; Sutton, 2006).

Assuming a translational method, otherwise referred to as "multimodal communicative competence" to analyze interactions between a user and a technology, allows researchers to understand the mediation effects on the communication processes (Royce, 2002, p. 192). Through considering the type of language used and the semiotic resources deployed, as well as various intrinsic and extrinsic structural affordances of the given medium, research can explore how meaning manifests within the bi-directional relationships fostered by BCI user-system interactions. Using an architectural model of physical spaces through three functions of analysis (experiential, interpersonal and textual), O'Halloran (2004) describes how a systemicfunctional approach, or a "social semiotic" approach to interactions that occur between a user and a technology, can offer a way to build knowledge and enhance meaning (p. 27), and further inform "somatechnological" conceptualizations of these tools as user-specific sites for embodied communicative exchanges (Eco, 1976; Rosenberger and VerBeek, 2015, p. 21).

\section{MEDIATION OF EXPERIENCE THROUGH TECHNOLOGY-ENABLED COMMUNICATION TOOLS}

As the social means of communicating become increasingly intertwined with practices within medical industries, we find ourselves relying more on these technologies to both educate and assess our own personal health and manage our personal relationships, as a key component of technological implementation rests on the ability to effectively demonstrate how emerging innovation may function within the larger context of a technologically dependent society (Tarhini et al., 2015). Technological development is often accompanied by a process that involves modifying and altering emerging technologies in ways that improve functional considerations, measures of efficiency, ease of use, technical properties of a new device or system; however, these changes can introduce intermediary shifts that can occur surrounding existing practices and uses for a given technology. This adjustment occurs in part, because of technological characteristics that have changed, but also due to evolving user needs (Webster, 2002; Schulz, 2004; Cox and Depoe, 2015). The dynamic relationship between new and existing technologies is translational, in that the future impact of a technology is largely determined by its perceived use value as well as how it is received amongst professional and general communities.

BCIs are communication technologies as well as social technologies which require in-depth social, cultural, and technical analysis of the characteristics of the tools themselves, as well as the behavior that surrounds device use. Research analyzing BCI systems as social-communicative mediums emphasizes the potentiality of these to improve modes of agency and expression for users. However, additional consideration should be given to ethical and moral issues that can arise when technical changes are made to corresponding mediated environments. When specific technical constraints reinforced by digital architectures are placed upon the communication processes, it may lead to dependency and heteronomy amongst users (Dijck, 2013). This suggests that interface architecture plays a role in identity formation through the process of social interaction, and as such, efforts to examine the relationship between a specific environment and self-expression as it relates to BCI systems should not be conceived with a "one-size-fits-all" approach (Lowery and DeFleur, 1983; Postmes et al., 2005; Nisbet and Scheufele, 2009).

\section{CONCLUSION}

By its nature, BCI is a multidisciplinary field. Assuming an epistemological approach towards exploring the intersection of how these sophisticated technologies mediate communication, enable cognitively embodied interactions, and afford users the ability to share subjective and collective experiences can encourage novel conceptual understandings as to how new boundaries of digital and physical user-system interactions can explored and further applied (Scott et al., 2019; Hackett, 2008). With a focus on developing ways to contribute to therapeutic care, the goal of this work is to support the integration of creative art therapies into technological affordances of hybrid BCI systems, as this type of intervention could provide more engaging and expressive forms of treatment options to different populations, improve existing treatment options and access to care, and offer therapists a new treatment modality. By developing BCIs in a way that serves as a digital health intervention; one that engages brain activity and real-time interaction with therapeutic activities, it offers an application that combines creative expression with traditional neurofeedback practices to provide an alternative tool to improve emotional and physiological healing and recovery.

\section{DATA AVAILABILITY STATEMENT}

The original contributions presented in the study are included in the article/Supplementary Material, further inquiries can be directed to the corresponding author. 


\section{AUTHOR CONTRIBUTIONS}

All authors listed have made a substantial, direct, and intellectual contribution to the work and approved it for publication.

\section{REFERENCES}

Angheluta, A., and Lee, B. K. (2011). Art Therapy for Chronic Pain: Applications and Future Directions. Can. J. Couns. Psychother. 45 (2), 112-131. Available at https://files.eric.ed.gov/fulltext/EJ930794.pdf.

Bamdad, M., Zarshenas, H., and Auais, M. A. (2015). Application of BCI Systems in Neurorehabilitation: A Scoping Review. Disabil. Rehabil. Assistive Techn. 10 (5), 355-364. doi:10.3109/17483107.2014.961569

Botrel, L., Holz, E. M., and Kübler, A. (2015). Brain Painting V2: Evaluation of P300-Based Brain-Computer Interface for Creative Expression by an End-User Following the User-Centered Design. Brain Comput. Inter. 2 (2-3), 135-149. doi:10.1080/2326263x.2015.1100038

Brunner, C., Birbaumer, N., Blankertz, B., Guger, C., Kübler, A., Mattia, D., et al. (2015). BNCI Horizon 2020: Towards a Roadmap for the Bci Community. Brain Comput. Inter. 2 (1), 1-10. doi:10.1080/2326263x.2015.1008956

Cox, R., and Depoe, S. (2015). "Emergence and Growth of the "Field" of Environmental Communications," in The Routledge Handbook of Environment and Communication. Editors A. Hansen and R. Cox (London: Routledge), 13-25.

Cruz-Garza, J. G., Chatufale, G., Robleto, D., and Contreras-Vidal, J. L. (2019). "Your Brain on Art: A New Paradigm to Study Artistic Creativity Based on the 'exquisite Corpse' Using mobile Brain-Body Imaging," in Brain Art. Editor A. Nijholt (Switzerland: Springer).

Daly, J. J., and Huggins, J. E. (2015). Brain-computer Interface: Current and Emerging Rehabilitation Applications. Arch. Phys. Med. Rehabil. 96 (3), S1-S7. doi:10.1016/j.apmr.2015.01.007

de Witte, M., Orkibi, H., Zarate, R., Karkou, V., Sajnani, N., Malhotra, B., et al. (2021). From Therapeutic Factors to Mechanisms of Change in the Creative Arts Therapies: A Scoping Review. Front. Psychol. 12, 2525. doi:10.3389/ fpsyg.2021.678397

Dhindsa, K., Carcone, D., and Becker, S. (2017a). Toward an Open-Ended BCI: A User-Centered Coadaptive Design. Neural Comput. 29, 2742-2768. doi:10.1162/neco_a_01001

Dhindsa, K., Carcone, D., and Becker, S. (2017b). "A Brain-Computer Interface Based on Abstract Visual and Auditory Imagery: Evidence for an Effect of Artistic Training," in Augmented Cognition, Enhancing Cognition and Behavior in Complex Human Environments. AC 2017, Part II, LNAI 10285. Editors D. D. Schmorrow and C. M. Fidopiastis (Springer International Publishing AG), 313-332. doi:10.1007/978-3-319-58625-0_23

D. Tan and A. Nijholt (Editors) (2010). Brain-computer Interfaces: Applying Our Minds to Human-Computer Interaction (London: Springer-Verlag). doi:10.1007/978-1-84996-272-8

Eco, U. (1976). A Theory of Semiotics. Bloomington: Indiana University Press.

Ehresman, C. (2014). From Rendering to Remembering: Art Therapy for People with Alzheimer's Disease. Int. J. Art Ther. 19 (1), 43-51. doi:10.1080/ 17454832.2013.819023

Friedrich, E. V. C., Scherer, R., and Neuper, C. (2012). The Effect of Distinct Mental Strategies on Classification Performance for Brain-Computer Interfaces. Int. J. Psychophysiol. 84 (1), 86-94. doi:10.1016/j.ijpsycho.2012.01.014

Geertz, C. J. (1973). Interpretation of Cultures. New York: Basic Books.

Guba, E. S., and Lincoln, Y. S. (1994). "Competing Paradigms in Qualitative Research," in Handbook of Qualitative Research. Editors N. K. Denzin and Y. S. Lincoln (Thousand Oaks: Sage Publications), 105-117.

Hackett, E. J. (2008). The Handbook of Science and Technology Studies. 3rd ed. Cambridge, MA: MIT Press.

Huggins, J. E., Guger, C., Aarnoutse, E., Allison, B., Anderson, C. W., Bedrick, S., et al. (2019). Workshops of the Seventh International Brain-Computer Interface Meeting: Not Getting Lost in Translation. Brain Comput. Inter. 6 (3), 71-101. doi:10.1080/2326263X.2019.1697163

\section{ACKNOWLEDGMENTS}

The authors would like to thank Dr. Charles Anderson and Dr. Rosa Mikeal Martey for their continued support.

Idhe, D. (1990). Technology and the Lifeworld. Bloomington: Indiana University Press.

Kaimal, G. (2019). "Brain on Art Therapy-Understanding the Connections between Facilitated Visual Self-Expression, Health, and Well-Being," in Mobile Brain-Body Imaging and the Neuroscience of Art, Innovation and Creativity. Editors J. Contreras-Vidal, D. Robleto, J. Cruz-Garza, J. Azorín, and C. Nam (Cham: Springer), Vol. 10. doi:10.1007/978-3-030-24326-5_13

King, J. L., and Kaimal, G. (2019). Approaches to Research in Art Therapy Using Imaging Technologies. Front. Hum. Neurosci. 13, 159. doi:10.3389/ fnhum.2019.00159

King, J. L., and Parada, F. J. (2021). Using mobile Brain/body Imaging to advance Research in Arts, Health, and Related Therapeutics. Eur. J. Neurosci., 1-17. doi:10.1111/ejn.15313

King, J. L., and Pascuzzi, R. M. (2018). "Lateral Sclerosis and Related Disorders (ALS)," in Art and Expressive Therapies Within a Medical Model: Clinical Applications. Editors E.-A. Deborah and G. Morgan (New York, NY: Routledge), 121-126.

King, J. L., Kaimal, G., Konopka, L., Belkofer, C., and Strang, C. E. (2019). Practical Applications of Neuroscience-Informed Art Therapy. Art Ther. 36, 149-156. doi:10.1080/07421656.2019.1649549

King, J. L. (2016). Art Therapy, Trauma, and Neuroscience: Theoretical and Practical Perspectives. New York: Routledge.

King, J. L. (2018). Summary of Twenty-First century Great Conversations in Art, Neuroscience and Related Therapeutics. Front. Psychol. 9, 1428. doi:10.3389/ fpsyg.2018.01428

Kübler, A., and Botrel, L. (2019). "The Making of Brain Painting-From the Idea to Daily Life Use by People in the Locked-In State," in Brain Art. Editor A. Nijholt (Switzerland: Springer).

Kubler, A., Holz, E., Kaufmann, T., and Zickler, C. (2013). "A User Centred Approach for Bringing BCI Controlled Applications to End-Users," in Braincomputer Interface Systems-Recent Progress and Future Prospects. Editor R. Fazel-Rezai (London: Tech Open Limited). doi:10.5772/55802

Kübler, A., Holz, E. M., Sellers, E. W., and Vaughan, T. M. (2015). Toward Independent home Use of Brain-Computer Interfaces: A Decision Algorithm for Selection of Potential End-Users. Arch. Phys. Med. Rehabil. 96 (3), S27-S32. doi:10.1016/j.apmr.2014.03.036

Lakoff, G., and Johnson, M. (2003). Metaphors We Live by. Chicago: University of Chicago Press.

Latour, B. (2009). Spheres and Networks: Two Ways to Reinterpret Globalization. Harv. Des. Mag. 30, 138-144. Available at https://hal-sciencespo.archivesouvertes.fr/hal-01022658.

Lincoln, Y. S., and Guba, E. G. (1989). Ethics: The Failure of Positivist Science. Rev. Higher Educ. 12 (3), 221-240. doi:10.1353/rhe.1989.0017

Lowery, S. A., and De Fleur, M. L. (1983). "Developing Frameworks for Studying Mass Communication," in Milestones in Mass Communication Research (New York: Longman), 1-29.

Morone, G., Pisotta, I., Pichiorri, F., Kleih, S., Paolucci, S., Molinari, M., et al. (2015). Proof of Principle of a Brain-Computer Interface Approach to Support Poststroke Arm Rehabilitation in Hospitalized Patients: Design, Acceptability, and Usability. Arch. Phys. Med. Rehabil. 96 (3), S71-S78. doi:10.1016/ j.apmr.2014.05.026

Muller-Putz, G., Leeb, R., Tangermann, M., Hohne, J., Kubler, A., Cincotti, F., et al. (2015). Towards Noninvasive Hybrid Brain-Computer Interfaces: Framework, Practice, Clinical Application, and beyond. Proc. IEEE 103 (6), 926-943. doi:10.1109/JPROC.2015.2411333

Nijholt, A. (2019). "Introduction: Brain-Computer Interfaces for Artistic Expression," in Brain Art. Editor A. Nijholt (Switzerland: Springer). doi:10.1007/978-3-030-14323-7_1

Nisbet, M. C., and Scheufele, D. A. (2009). What's Next for Science Communication? Promising Directions and Lingering Distractions. Am. J. Bot. 96, 1767-1778. doi:10.3732/ajb.0900041 
Nishimura, E. M., Rapoport, E. D., Wubbels, P. M., Downs, T. H., and Downs, J. H. (2010). "Functional Near-Infrared Sensing (fNIR) and Environmental Control Applications," in Brain-Computer Interfaces. Human-Computer Interaction Series. Editors D. Tan and A. Nijholt (London: Springer). doi:10.1007/9781-84996-272-8_8

O’Halloran, K. L. (2004). Multimodal Discourse Analysis: Systemic-Functional Perspectives. London: Continuum.

Orndorff-Plunkett, F., Singh, F., Aragón, O., and Pineda, J. (2017). Assessing the Effectiveness of Neurofeedback Training in the Context of Clinical and Social Neuroscience. Brain Sci. 7 (8), 95. doi:10.3390/brainsci7080095

Postmes, T., Haslam, S. A., and Swaab, R. I. (2005). Social Influence in Small Groups: An Interactive Model of Social Identity Formation. Eur. Rev. Soc. Psychol. 16 (1), 1-42. doi:10.1080/10463280440000062

Rapoport, E. D., Nishimura, E. M., Zadra, J. R., Wubbels, P. M., Proffitt, D. R., Downs, T. H., et al. (2008). Engaging, Non-Invasive Brain-Computer Interfaces (BCIs) for Improving Training Effectiveness \& Enabling Creative Expression. Proc. Hum. Factors Ergon. Soc. Annu. Meet. 52 (7), 591-594. doi:10.1177/ 154193120805200702

Rosenberger, R., and VerBeek, P. P. (2015). Postphenomenological Investigations: Essays on Human-Technology Relations. Lanham, MD: Lexington Books.

Royce, T. (2002). Multimodality in the TESOL Classroom: Exploring VisualVerbal Synergy. TESOL Q. 36 (2), 191-205. doi:10.2307/3588330

Salomon, G. (1997). Distributed Cognitions: Psychological and Educational Considerations. Cambridge, UK: Cambridge University Press.

Schulz, W. (2004). Reconstructing Mediatization as an Analytical Concept. Eur. J. Commun. 19 (1), 87-101. doi:10.1177/0267323104040696

Scott, S. M., and Gehrke, L. (2019). "Neurofeedback during Creative Expression as a Therapeutic Tool," in Mobile Brain-Body Imaging and the Neuroscience of Art, Innovation and Creativity. Editors J. L. Contreras-Vidal, D. Robleto, J. G. CruzGarza, J. M. Azorín, and C. Nam (Switzerland: Springer International Publishing), 161-166. doi:10.1007/978-3-030-24326-5_17

Scott, S. M., Raftery, C., and Anderson, C. (2019). "Brain Art," in Brain Art: BrainComputer Interfaces for Artistic Expression. Editor A. Nijholt. 1st ed. (Switzerland: Springer International Publishing). doi:10.1007/978-3-03014323-7

Sonke, J. (2016). "Professionalizing the Arts in Healthcare Field," in Managing Arts Programs in Healthcare. Editor P. D. Lambert (New York: Routledge), 32-44.

Stewart, E. G. (2004). Art Therapy and Neuroscience Blend: Working with Patients Who Have Dementia. Art Ther. 21, 148-155. doi:10.1080/ 07421656.2004.10129499

Sutton, J. (2006). Distributed Cognition. PC 14 (2), 235-247. doi:10.1075/ pc.14.2.05sut
Tarhini, A., Hone, K, and Liu, X. (2015). A Cross-Cultural Examination of the Impact of Social, Organisational and Individual Factors on Educational Technology Acceptance between British and Lebanese university Students. Br. J. Educ. Technol. 46, 739-755. doi:10.1111/bjet.12169

Todd, D. A., Mccullagh, P. J., Mulvenna, M. D., and Lightbody, G. (2012). "Investigating the Use of Brain- Computer Interaction to Facilitate Creativity," in Proceedings of the 3rd Augmented Human International Conference, Megève, France, March 1-8, 2012. doi:10.1145/2160125.2160144 van Dijck, J. (2013). 'You Have One Identity': Performing the Self on Facebook and LinkedIn. Media, Cult. Soc. 35, 199-215. doi:10.1177/0163443712468605

Webster, A. (2002). Innovative Health Technologies and the Social: Redefining Health, Medicine and the Body. Curr. Sociol. 50 (3), 443-457. doi:10.1177/ 0011392102050003009

Wolpaw, J., and Wolpaw, E. W. (2012). Brain-computer Interfaces: Principles and Practice. New York: Oxford University Press.

Wolpaw, J. R., Birbaumer, N., McFarland, D. J., Pfurtscheller, G., and Vaughan, T. M. (2002). Brain-computer Interfaces for Communication and Control. Clin. Neurophysiol. 113 (6), 767-791. doi:10.1016/S1388-2457(02)00057-3

Zhang, J., and Norman, D. A. (1994). Representations in Distributed Cognitive Tasks. Cogn. Sci. 18, 87-122. doi:10.1207/s15516709cog1801_3

Zhang, J., and Patel, V. L. (2006). Distributed Cognition, Representation, and Affordance. PC 14 (2), 333-341. doi:10.1075/pc.14.2.12zha

Zickler, C., Halder, S., Kleih, S. C., Herbert, C., and Kübler, A. (2013). Brain Painting: Usability Testing According to the User-Centered Design in End Users with Severe Motor Paralysis. Artif. Intell. Med. 59 (2), 99-110. doi:10.1016/j.artmed.2013.08.003

Conflict of Interest: The authors declare that the research was conducted in the absence of any commercial or financial relationships that could be construed as a potential conflict of interest.

Publisher's Note: All claims expressed in this article are solely those of the authors and do not necessarily represent those of their affiliated organizations, or those of the publisher, the editors and the reviewers. Any product that may be evaluated in this article, or claim that may be made by its manufacturer, is not guaranteed or endorsed by the publisher.

Copyright (c) 2021 Scott and Raftery. This is an open-access article distributed under the terms of the Creative Commons Attribution License (CC BY). The use, distribution or reproduction in other forums is permitted, provided the original author(s) and the copyright owner(s) are credited and that the original publication in this journal is cited, in accordance with accepted academic practice. No use, distribution or reproduction is permitted which does not comply with these terms. 